\title{
Hydrazide Derivatives: An Overview of Their Inhibition Activity against Acid Corrosion of Mild Steel
}

\author{
Prakash Shetty \\ Department of Chemistry, Manipal Institute of Technology, Manipal Academy of Higher Education (A Deemed University), \\ Manipal-576104, Karnataka, India \\ E-mail:prakash.shetty@manipal.edu
}

Received 21 June 2017, revised 6 October 2017, accepted 4 November 2017.

\begin{abstract}
This paper gives an overview of the application of hydrazide derivatives in acid media as corrosion inhibitors of mild steel. In chemical and petrochemical industries, mild steel is the major constructional material widely used. Acid solutions have been commonly used in these industries as pickling agents to remove rust or any scale from the mild steel surface. The excessive dissolution of mild steel in such aggressive medium can be best controlled by addition of suitable organic inhibitors. Hydrazide derivatives are widely used in such applications as mild steel corrosion inhibitors. The various factors which influence the corrosion inhibition efficiency of different hydrazide derivatives have been discussed. The information provided is useful for various industries where corrosion inhibitors are needed to protect mild steel structures which are being exposed to hydrochloric or sulphuric acid solutions.
\end{abstract}

KEYWORDS

Hydrazide derivatives, mild steel, acid media, corrosion inhibition, adsorption.

Table of Contents

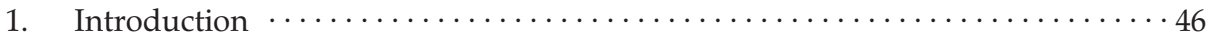

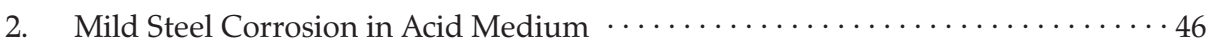

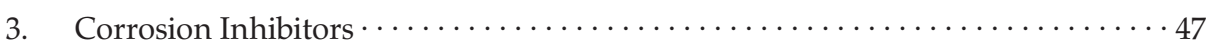

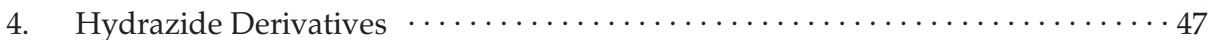

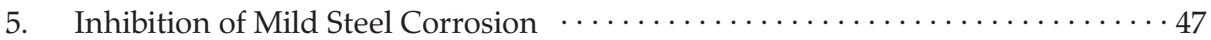

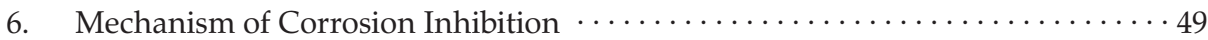

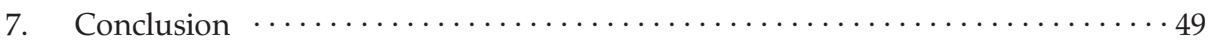

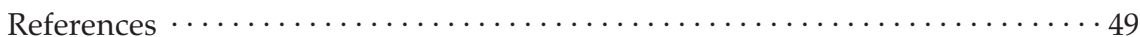

\section{Introduction}

Corrosion is an undesirable process that takes place by the reaction of an engineering material (such as metals, alloys) with its environment resulting in changes in the properties of the material. This may often lead to impairment of the function of the material and possibly the environment. The corrosion process usually occurs through chemical or electrochemical reactions because of the natural tendency of pure metals to return back to their thermodynamically stable compound state. Metallic corrosion is considered as a global calamity of major importance and costs about several billion dollars every year. ${ }^{1}$ Therefore, it is necessary to give prime importance to metallic corrosion because of the increasing use of metals in all fields of technology and increasing pollution resulting in the more corrosive environment. Corrosion inhibition studies are also important to conserve the world metal resources by putting control over metallic corrosion. Hence, research and development in the field of corrosion and corrosion inhibition finds great importance in order to reduce corrosion damages and to conserve economic resources of the nation in all branches of technology. ${ }^{2}$

\section{Mild Steel Corrosion in Acid Medium}

Mild steel is a carbon steel which contains up to $0.3 \%$ carbon.
It finds wide applications in chemical, petrochemical, and oil refinery industry because of its good mechanical properties and low cost. ${ }^{3}$ Mild steel is an important material of construction for chemical storage tanks, oil and gas pipelines, heat exchangers and boiler systems. Acid solutions are employed as pickling and descaling agents in many industries. Among the mineral acids, hydrochloric and sulphuric acids are commonly used in such applications. However, the usage of hydrochloric acid in such industrial applications is economical, efficient and trouble-free. ${ }^{4}$

In acid chloride solution, the dissolution of mild steel may be represented as ${ }^{5}$

$$
\begin{array}{ll}
\mathrm{Fe}+\mathrm{Cl}^{-} \longrightarrow \mathrm{FeCl}_{\text {ads }}^{-} & 1 \mathrm{a} \\
\mathrm{FeCl}^{-}{ }_{\text {ads }} \longrightarrow \mathrm{FeCl}^{+}{ }_{\text {ads }}+2 \mathrm{e}^{-} & 1 \mathrm{~b} \\
\mathrm{FeCl} \longrightarrow \mathrm{Fe}^{2+}-\mathrm{Cl}^{-} & 1 \mathrm{c}
\end{array}
$$

In acid sulfate solution, the dissolution of mild steel may be represented as ${ }^{6}$

$$
\begin{array}{ll}
\mathrm{Fe}+\mathrm{H}_{2} \mathrm{O} \longrightarrow \mathrm{FeOH}_{\mathrm{ads}}+\mathrm{H}^{+}+\mathrm{e}^{-} & 2 \mathrm{a} \\
\mathrm{FeOH}_{\mathrm{ads}} \longrightarrow \mathrm{FeOH}^{+}+\mathrm{e}^{-} & 2 \mathrm{~b} \\
\mathrm{FeOH}^{+}+\mathrm{H}^{+} \longrightarrow \mathrm{Fe}^{2+}+\mathrm{H}_{2} \mathrm{O} & 2 \mathrm{c}
\end{array}
$$

Mostly a convenient and economical method for controlling 
metallic corrosion is the proper modification of the corrosive medium by the addition of the suitable inhibitor.

\section{Corrosion Inhibitors}

The corrosion inhibitor is a substance which upon adding in small quantities to the corroding medium drastically reduces the corrosion rate of metals. They are usually added either continuously or intermittently in small amounts to the corrosive medium to provide required control against corrosion. The selection of suitable corrosion inhibitor for any application depends on the nature of the metal, the concentration, temperature, and flow rate of the corrosive medium. An inhibitor can control the rate of corrosion either by reducing the rate of anodic or cathodic or both corrosion reactions. Depending upon the mode of their action, corrosion inhibitors may be classified as anodic, cathodic and mixed type inhibitors.

Anodic inhibitors usually control the anodic reaction by polarizing it and shifting the corrosion potential towards the positive direction. This decreases the corrosion current and finally controls the corrosion rate. Chromates, nitrates, tungstate, and molybdates are some examples for anodic inhibitors. On the other hand, cathodic inhibitors control cathode reaction by polarizing it and displacing the corrosion potential towards the negative direction. They retard the cathodic reaction and reduce the corrosion rate. Examples of cathodic inhibitors are phosphates, silicates and borates. Substances which control both cathodic and anodic reaction are called mixed inhibitors. Generally, organic compounds act as mixed inhibitors which control both metal dissolution and cathodic reaction. Hence they reduce the corrosion rate and control corrosion. Organic corrosion inhibitors are extensively employed in chemical, petrochemical and oil exploration industries. Therefore, the development of new organic corrosion inhibitors which are less costly with improved performance and better environmental profiles is essential. The following factors become important while selecting a suitable organic corrosion inhibitor: (i) it should be readily available and cheap; (ii) the inhibitor molecule should have heteroatoms $(\mathrm{N}, \mathrm{O}$, or S), multiple bonds and/or aromatic rings. Such compounds show better adsorption and inhibition performance; (iii) it should be soluble and stable in the medium where it is being used and (iv) it should be environmentally friendly.

\section{Hydrazide Derivatives}

Hydrazides derivatives are the type of organic compounds containing a nitrogen-nitrogen covalent bond with one of the substituents being an acyl group. Hydrazides and their derivatives have gained prominence because of their antibacterial, anti-inflammatory, anticancer, antiplatelet, antimalarial, analgesic and antioxidant activity. ${ }^{8,9}$ In addition to this they are also employed as potential inhibitors for controlling corrosion of many metals including mild steel.

\section{Inhibition of Mild Steel Corrosion}

Literature survey reveals that hydrazide derivatives have been extensively studied for their corrosion inhibitive performance in acid medium towards mild steel.

The inhibitory effect of some acid hydrazides ${ }^{10}$ namely, salicylic acid hydrazide $\left(\mathrm{HD}_{1}\right)$, anthranilic acid hydrazide $\left(\mathrm{HD}_{2}\right)$, benzoic acid hydrazide $\left(\mathrm{HD}_{3}\right)$ and cinnamic acid hydrazide $\left(\mathrm{HD}_{4}\right)$, and also some oleochemical based hydrazides ${ }^{11}$ like decanohydrazide $\left(\mathrm{HD}_{5}\right)$, dodecanohydrazide $\left(\mathrm{HD}_{6}\right)$, hexadecanohydrazide $\left(\mathrm{HD}_{7}\right)$, and octadecanohydrazide $\left(\mathrm{HD}_{8}\right)$ in $1 \mathrm{M}$ $\mathrm{HCl}$ medium towards corrosion of mild steel have been investi- gated. The inhibition performance of all the tested compounds increased with their concentration. The adsorption of the acid hydrazides $\left(\mathrm{HD}_{1}, \mathrm{HD}_{2}, \mathrm{HD}_{3} \& \mathrm{HD}_{4}\right)$ followed Temkin adsorption isotherm, whereas that of oleochemical hydrazides $\left(\mathrm{HD}_{5}, \mathrm{HD}_{6}\right.$, $\mathrm{HD}_{7} \& \mathrm{HD}_{8}$ ) obeyed Langmuir adsorption isotherm. The polarization results indicate the mixed inhibitor behaviour of the compounds except for $\mathrm{HD}_{1}$, which has shown cathodic type behaviour. In the case of acid hydrazides the inhibition performance was found to be in the order: $\mathrm{HD}_{1}<\mathrm{HD}_{2}<\mathrm{HD}_{3}<\mathrm{HD}_{4^{\prime}}$ whereas in oleochemical hydrazides it was found to be in the order: $\mathrm{HD}_{8}<\mathrm{HD}_{7}<\mathrm{HD}_{5}<\mathrm{HD}_{6}$. Inhibition efficiency of acid hydrazides decreased $\left(\mathrm{HD}_{1}: 38\right.$ to $36 \%, \mathrm{HD}_{2}: 39$ to $34 \%, \mathrm{HD}_{3}$ : 87 to $85 \%$ and $\mathrm{HD}_{4}: 92$ to $87 \%$ ) with an increase in temperature (35 to $65^{\circ} \mathrm{C}$ ) at $500 \mathrm{ppm}$.

Larabi et al. ${ }^{12}$ have investigated the influence of hydrazide derivatives such as oxalic N-phenylhydrazide-N'-phenylthiosemicarbazide $\left(\mathrm{HD}_{9}\right)$ and $\mathrm{N}$-phenyl oxalic dihydrazide $\left(\mathrm{HD}_{10}\right)$ in $1 \mathrm{M} \mathrm{HCl}$ towards corrosion inhibition of mild steel by electrochemical measurements. Both the tested compounds acted as mixed inhibitor and their adsorption followed Langmuir isotherm model. The adsorption of compounds $\mathrm{HD}_{9}$ and $\mathrm{HD}_{10}$ take place by chemisorption and physisorption, respectively. The maximum efficiency of $92 \%\left(\mathrm{HD}_{9}\right)$ and $79 \%$ $\left(\mathrm{HD}_{10}\right)$ respectively are obtained at $5 \times 10^{-4} \mathrm{M}$ concentration and $298 \mathrm{~K}$. The inhibition efficiency of $\mathrm{HD}_{9}$ increased ( 92 to $96 \%$ ) and $\mathrm{HD}_{10}$ decreased (78 to $73 \%$ ) with the rise in temperature (298 to $318 \mathrm{~K})$.

Shanbhag et al. ${ }^{13}$ have reported the application of some hydrazide derivative such as $\mathrm{N}^{\prime}$-[(1E)-(4-hydroxy phenyl) methylene] isonicotinohydrazide $\left(\mathrm{HD}_{11}\right)$ and $\mathrm{N}^{\prime}$-[(1E)-(4-hydroxyl3-methoxy phenyl) methylene] isonicotinohydrazide $\left(\mathrm{HD}_{12}\right)$ in $1 \mathrm{M} \mathrm{HCl}$ medium as mild steel corrosion inhibitors. Inhibitory efficiency of both the compounds increased with their concentration but decreased ( 74 to $54 \%$ for $\mathrm{HD}_{11}$ and 81 to $56 \%$ for $\mathrm{HD}_{12}$ ) with the rise in temperature ( 303 to $333 \mathrm{~K}$ ). The results of weight loss method showed a maximum efficiency of $74 \%\left(\mathrm{HD}_{11}\right)$ and $81 \%\left(\mathrm{HD}_{12}\right)$ at $25 \times 10^{-5} \mathrm{M}$ concentration, respectively. Both the tested compounds acted as mixed inhibitor and their adsorption followed Langmuir isotherm model. The scanning electron microscopy (SEM) images and Fourier transform infrared (FTIR) spectra of the inhibited samples clearly indicated the formation of a film on mild steel surface.

Saliyan and Adhikari have tested the inhibition behaviour of Quinolin-5-ylmethylene-3-\{[8-(trifluoromethyl)quinolin-4-yl] thio p propanohydrazide $\left(\mathrm{HD}_{13}\right){ }^{14}$ in 1 and $2 \mathrm{M} \mathrm{HCl}$ solution towards corrosion of mild steel and they also studied the inhibitory action of 3-\{[8-(triflouromethyl) quinolene-4-yl]thio $\}-\mathrm{N}^{\prime}-$ (2,3,4-trihydroxybenzylidine) propane hydrazide $\left(\mathrm{HD}_{14}\right)^{15}$ in $\mathrm{HCl}$ and $\mathrm{H}_{2} \mathrm{SO}_{4}$ media towards mild steel. Both the compounds $\mathrm{HD}_{13}$ and $\mathrm{HD}_{14}$ acted as an anodic inhibitor. The adsorption of both the compounds takes place by chemisorption and followed Langmuir adsorption isotherm. Inhibition efficiency of tested compounds $\left(\mathrm{HD}_{13} \& \mathrm{HD}_{14}\right)$ increased with their concentration. It was found that increase in solution temperature decreased the inhibitory efficiency of compound $\mathrm{HD}_{13}$ but increased the inhibitory efficiency of compound $\mathrm{HD}_{14}$. The compound $\mathrm{HD}_{13}$ showed the maximum inhibitory efficiency of $91 \%$ in $1 \mathrm{M} \mathrm{HCl}$ and $86 \%$ in $2 \mathrm{M} \mathrm{HCl}$ respectively at $500 \mathrm{ppm}$ concentration and at $40{ }^{\circ} \mathrm{C}$. The compound $\mathrm{HD}_{14}$ showed the maximum efficiency of $94.8 \%$ in $1 \mathrm{M} \mathrm{HCl}$ and $98.5 \%$ in $0.5 \mathrm{M} \mathrm{H}_{2} \mathrm{SO}_{4}$ respectively at $11.086 \times$ $10^{-4} \mathrm{M}$ concentration and at $60^{\circ} \mathrm{C}$.

The inhibition effect of $N^{\prime}, N^{\prime}$-Dialkylhydrazides $\left[\mathrm{C}_{4} \mathrm{H}_{9} \mathrm{CH}\right.$ $\left(\mathrm{C}_{2} \mathrm{H}_{5}\right) \mathrm{C}(\mathrm{O}) \mathrm{NHN}(\mathrm{R})_{2}, \mathrm{R}=\mathrm{C}_{2} \mathrm{H}_{5}\left(\mathrm{HD}_{15}\right), \mathrm{C}_{3} \mathrm{H}_{7}\left(\mathrm{HD}_{16}\right), \mathrm{C}_{4} \mathrm{H}_{9}\left(\mathrm{HD}_{17}\right)$, 
$\left.\mathrm{C}_{5} \mathrm{H}_{11}\left(\mathrm{HD}_{18}\right)\right]$ in 0.1 and $1 \mathrm{M} \mathrm{HCl}$ as corrosion inhibitor of ST 20 steel has been studied by Shcherban et al. ${ }^{16}$ using electrochemical and gravimetric methods. The tested hydrazide compounds have acted as a mixed inhibitor. An increase in chain length $(R=$ $\mathrm{C}_{2} \mathrm{H}_{5}$ to $\mathrm{C}_{5} \mathrm{H}_{11}$ ) of the hydrazide resulted in the increase of inhibition power. Hydrazide $\mathrm{HD}_{18}$ showed the maximum efficiency of $73 \%$ at $0.1 \mathrm{~g} \mathrm{~L}^{-1}$ in $1 \mathrm{M} \mathrm{HCl}$. Toliwal and Jadav ${ }^{17}$ have synthesized 2-alkyl-N-methylenehydrazinecabothiaoamide of fatty acid hydrazides from neem $\left(\mathrm{HD}_{19}\right)$, rice ban $\left(\mathrm{HD}_{20}\right)$ and karanja $\left(\mathrm{HD}_{21}\right)$ oils, and evaluated their performance in hydrochloric acid solution as inhibitors against mild steel corrosion by weight loss method. All the hydrazide derivatives acted as mixed inhibitors and their adsorption obeyed Langmuir isotherm model. Inhibition performance of these compounds increased with their concentration, acid concentration up to $3 \mathrm{~N}$ and solution temperature $\left(30-50{ }^{\circ} \mathrm{C}\right)$. Further increase in acid concentration up to $5 \mathrm{~N}$ caused a decrease in inhibition efficiency because of increased aggressiveness of the acid medium. The order of inhibition efficiency of these hydrazide derivatives was found to be $\mathrm{HD}_{19}<$ $\mathrm{HD}_{20}<\mathrm{HD}_{21}$. The maximum inhibition efficiencies shown by these compounds in $1 \mathrm{~N} \mathrm{HCl}$ are $83 \%\left(\mathrm{HD}_{19}\right), 86\left(\mathrm{HD}_{20}\right)$ and $89\left(\mathrm{HD}_{21}\right)$ respectively at $500 \mathrm{ppm}$ concentration.

Khaled et al. ${ }^{18}$ have studied the inhibitive performance of 3-pyridinecarboxaldehyde thiosemicarbazone $\left(\mathrm{HD}_{22}\right)$ in $1 \mathrm{M}$ $\mathrm{HCl}$ solution towards the corrosion of mild steel. The efficiency of the inhibitor compound increased with its concentration whereas it decreased with a rise in solution temperature. The compound $\mathrm{HD}_{22}$ showed mixed inhibitor behaviour. Maximum inhibition efficiency of $94 \%$ was obtained at $10^{-2} \mathrm{M}$ concentration of $\mathrm{HD}_{22}$ and at $30^{\circ} \mathrm{C}$. Inhibition takes place by mixed adsorption and followed Langmuir adsorption isotherm model. A study on the inhibition performance of benzo hydrazide derivatives such as N-benzylidene benzo hydrazide $\left(\mathrm{HD}_{23}\right)$ and $\mathrm{N}^{\prime}$-(3-phenylallylidene) benzo hydrazide $\left(\mathrm{HD}_{24}\right)$ in $1 \mathrm{M} \mathrm{HCl}$ towards corrosion of mild steel has been reported. ${ }^{19}$ The inhibition performance of these compounds increased with their concentration and decreased with a rise in temperature. The adsorption takes place through chemisorption and obeyed Langmuir isotherm model. Maximum inhibition efficiency obtained was $97 \%$ at the optimal inhibitor concentration. The surface morphology analysis confirmed the film formation by inhibitor molecules on mild steel surface. Chakravarthy and Mohana ${ }^{20}$ have reported the synthesis of some isonicotinic acid hydrazides namely, isonicotinic acid (1H-indol-3-yl-methylene)hydrazide $\left(\mathrm{HD}_{25}\right)$ and isonicotinic acid (1H-pyrrol-2-yl-methylene)hydrazide $\left(\mathrm{HD}_{26}\right)$, and study of their inhibitive characteristics in $0.5 \mathrm{M} \mathrm{HCl}$ against corrosion of mild steel. Polarization results indicated the mixed type behaviour of compounds, $\mathrm{HD}_{25}$ and $\mathrm{HD}_{26}$. The inhibitory performance of both the compounds increased with their concentration and decreased with a rise temperature from 30 to $60{ }^{\circ} \mathrm{C}$. Adsorption of both the inhibitor compounds followed Langmuir adsorption isotherm. Maximum inhibitor efficiency greater than $80 \%$ was obtained by both $\mathrm{HD}_{25}$ and $\mathrm{HD}_{26}$ at $500 \mathrm{ppm}$ in $0.5 \mathrm{M} \mathrm{HCl}$ solution at $30^{\circ} \mathrm{C}$. The protective film formation by inhibitor compounds on mild steel surface has been confirmed by SEM images and spectral analysis.

Fouda et al. ${ }^{21}$ have reported the corrosion inhibition behaviour of some benzo hydrazide derivatives like (E)-N'-(furan-2-yl) methylene)-2-methyl benzo hydrazide $\left(\mathrm{HD}_{27}\right),(\mathrm{E})-\mathrm{N}^{\prime}$-((furan2-yl) methylene)-hydroxy benzo hydrazide $\left(\mathrm{HD}_{28}\right)$ and (E)-2chloro-N'-(furan-2-yl) methylene) benzo hydrazide $\left(\mathrm{HD}_{29}\right)$ in $2 \mathrm{M} \mathrm{HCl}$ medium against mild steel at $30^{\circ} \mathrm{C}$. Inhibition performance of these compounds increased with their concentration and decreased with rise in temperature. The tested compounds have showed mixed inhibitor behaviour. The maximum inhibitory efficiency of more than $80 \%$ was obtained at $15 \times 10^{-5} \mathrm{M}$ concentration of all the tested compounds. The adsorption of all the inhibitors obeyed Temkin adsorption isotherm and adsorption takes place through physisorption. The presence of halide ions $\left(\mathrm{Cl}^{-}\right.$and $\left.\mathrm{Br}^{-}\right)$has increased the inhibition efficiency of these benzo hydrazide derivatives due to a synergistic effect.

Pradeep Kumar and Mohana ${ }^{22}$ have examined the inhibition properties of hydrazide derivatives namely, 4-(4-bromophenyl)- $\mathrm{N}^{\prime}$-(2,4-dimethoxybenzylidene)thiazole-2-carbohydrazide $\left(\mathrm{HD}_{30}\right)$, 4-(4-bromo phenyl)- $\mathrm{N}^{\prime}$-(4-methoxybenzyl idene)thiazole-2-carbohydrazide $\left(\mathrm{HD}_{31}\right)$, and 4-(4-bromo phenyl)-N'-(4-hydroxy benzylidene) thiazole-2 carbohydrazide $\left(\mathrm{HD}_{32}\right)$ in $0.5 \mathrm{M} \mathrm{HCl}$ medium against mild steel corrosion. The polarization results indicated the mixed type behaviour of all the tested compounds. Inhibition power of all the compounds increased with their concentration whereas it decreased with a rise in temperature. Inhibition takes place through mixed adsorption and followed Langmuir isotherm model. The inhibition performance of the tested compounds followed the decreasing order: $\mathrm{HD}_{30}>\mathrm{HD}_{32}>\mathrm{HD}_{31}$. The maximum inhibition efficiency of $91 \%$ was obtained by the compound $\mathrm{HD}_{30}$ at $1.1 \mathrm{mM}$ concentration. The height inhibition efficiency showed by the compound $\mathrm{HD}_{30}$ was due to the two methoxy groups attached to the aromatic ring.

Gupta et al. ${ }^{23}$ have evaluated the corrosion inhibition performance of ferrocene carboxaldehyde propanoylhydrazone $\left(\mathrm{HD}_{33}\right)$ and ferrocene carboxaldehyde furoylhydrazone $\left(\mathrm{HD}_{34}\right)$ in $0.5 \mathrm{M} \mathrm{H}_{2} \mathrm{SO}_{4}$ towards mild steel at $298 \mathrm{~K}$. As concentration increases, corrosion inhibition property of the compounds also increases. The compound $\mathrm{HD}_{34}$ has shown better inhibition efficiency than $\mathrm{HD}_{33}$. The presence of extra oxygen atom and $\pi$-electrons of furan ring in $\mathrm{HD}_{34}$ enhanced its adsorption and hence increased the efficiency. The maximum inhibitory efficiency of $91 \%$ was obtained by the compound $\mathrm{HD}_{34}$ at 100 ppm concentration.

Preethi Kumari et al. have reported the corrosion inhibition properties of (2E)-2-(3-hydroxy-2-methoxybenzylidene) hydrazine carbothioamide $\left(\mathrm{HD}_{35}\right)^{24,25}$ and 2-(3,4,5-trimethoxy benzylidene)hydrazine carbothioamide $\left(\mathrm{HD}_{36}\right)^{26}$ in $\mathrm{HCl}$ solution against mild steel using Tafel polarization and electron impedance spectroscopy (EIS) methods. Polarization results indicated the mixed inhibitor behaviour of all the tested compounds. Inhibition takes place by mixed adsorption and followed Langmuir isotherm model. Inhibition performance all these compounds increased with their concentration and medium temperature. The maximum inhibitor efficiency of $94 \%$ $\left(\mathrm{HD}_{35}\right)$ and $95 \%\left(\mathrm{HD}_{36}\right)$ was obtained respectively at $0.8 \mathrm{mM}$ concentration. The formation of protective films by adsorption of these inhibitors was confirmed by SEM images. The adsorption behaviours of $\mathrm{N}^{\prime}$-[4-(dimethylamino)benzylidene]-4hydroxybenzohydrazide $\left(\mathrm{HD}_{37}\right)^{27}, 4$-hydroxy-N'-[(E)-(1Hindole-2-ylmethylidene)] benzo hydrazide $\left(\mathrm{HD}_{38}\right)^{28}$ and 4-hydroxyN'-[(1E, 2E)-3-phenylprop-2-en-1-ylidene]benzohydrazide $\left(\mathrm{HD}_{39}\right)^{29}$ in $\mathrm{HCl}$ solution towards mild steel corrosion have been tested. The inhibition efficiency of all the tested compounds increased with increase in their concentration. It was observed that an increase in the solution temperature in the case of $\mathrm{HD}_{38}$ and $\mathrm{HD}_{39}$, and a decrease in the solution temperature in the case of $\mathrm{HD}_{37}$ have resulted in the increase of inhibition efficiency. All the tested compounds have showed mixed inhibitor behaviour. Inhibition takes place by mixed adsorption and followed Langmuir adsorption isotherm. The maximum inhibi- 
tion efficiency showed by the tested compounds at $60{ }^{\circ} \mathrm{C}$ are $84 \%\left(\mathrm{HD}_{37}\right.$ in $\left.2 \mathrm{M} \mathrm{HCl}\right), 94 \%\left(\mathrm{HD}_{38}\right.$ in $\left.\mathrm{IM} \mathrm{HCl}\right)$ and $92 \%\left(\mathrm{HD}_{39}\right.$ in $0.5 \mathrm{M} \mathrm{HCl})$, respectively.

Yadav et $a l .{ }^{30}$ have investigated the effect of acetohydrazides namely, $N^{\prime}$-[(1Z)- phenylmethylene]-2-(quinolin-8-yloxy) acetohydrazide $\left(\mathrm{HD}_{40}\right)$ and $\mathrm{N}^{\prime}-[(1 \mathrm{Z})$-4-chlorophenylmethylene]-2-(quinolin-8-yloxy) acetohydrazide $\left(\mathrm{HD}_{41}\right)$ in $15 \%$ $\mathrm{HCl}$ towards the corrosion of mild steel. The inhibition performance of both the compounds increased with their concentration, whereas it decreased with a rise in temperature. The compounds $\mathrm{HD}_{40}$ and $\mathrm{HD}_{41}$ have shown mixed inhibitor behaviour. The adsorption of the inhibitors takes place by mixed adsorption predominantly with physisorption and obeyed Langmuir adsorption isotherm. Atomic Force Microscopy, SEM, and Energy Dispersion X-ray Spectroscopy (EDX) results have confirmed the protective film on the mild steel. Maximum inhibitory efficiency exhibited at $400 \mathrm{ppm}$ was found to be $95.1 \%$ $\left(\mathrm{HD}_{40}\right)$ and $94.2 \%\left(\mathrm{HD}_{41}\right)$ respectively at $303 \mathrm{~K}$. Abdallah et al. ${ }^{31}$ have reported the synthesis of a new hydrazide derivative namely, 2-(2-hydrazinyl-1, 6-dihydro-6-oxopyrimidin-4-yl) aceto hydrazide $\left(\mathrm{HD}_{42}\right)$ and evaluated its inhibition activity in $1 \mathrm{M} \mathrm{HCl}$ and $0.5 \mathrm{M} \mathrm{H}_{2} \mathrm{SO}_{4}$ media towards mild steel corrosion. The inhibitor compound has showed better performance in $\mathrm{HCl}$ medium than that in the $\mathrm{H}_{2} \mathrm{SO}_{4}$ medium. The compound $\mathrm{HD}_{42}$ has showed cathodic inhibitor behaviour in both acid medium and maximum inhibition performance of $90 \%$ at $5 \times 10^{-2} \mathrm{M}$ in $\mathrm{HCl}$ solution. The adsorption takes place by physisorption of $\mathrm{HD}_{42}$ and followed Langmuir adsorption isotherm.

Al-Amiery et al..$^{32}$ have reported the corrosion inhibition study on mild steel using azelaic acid dihydrazide $\left(\mathrm{HD}_{43}\right)$ in $1 \mathrm{M} \mathrm{HCl}$ medium. Polarization measurements indicate the mixed type behaviour of inhibitor compound. The inhibition efficiency of the compound increased with its concentration whereas decreased with a rise in solution temperature. Maximum inhibitor efficiency of $93 \%$ was observed at $5 \times 10^{-3} \mathrm{M}$ and $30^{\circ} \mathrm{C}$. The adsorption process of the inhibitor molecules followed Langmuir isotherm model. The SEM images gave evidence for the formation of a film on mild steel surface. Mohd et al. ${ }^{33}$ have examined the inhibitive actions of fatty acid derivatives namely, palmitate hydrazide $\left(\mathrm{HD}_{44}\right)$, N-ethylidene palmitate hydrazide $\left(\mathrm{HD}_{45}\right)$ and $\mathrm{N}$-phenyl methylidene palmitate hydrazide $\left(\mathrm{HD}_{46}\right)$ in $1 \mathrm{MHCl}$ towards mild steel corrosion using linear polarization and EIS techniques. Inhibitor efficiency increased with inhibitor concentrations and temperature of the acid medium. All the tested compounds have showed mixed inhibitor behaviour. The inhibition performance was found to be in the order: $\mathrm{HD}_{46}>$ $\mathrm{HD}_{45}>\mathrm{HD}_{44}$. The compound, $\mathrm{HD}_{46}$ has shown better performance ( $85 \%$ at $200 \mathrm{mg} \mathrm{L}^{-1}$ and $308 \mathrm{~K}$ ) due to the phenyl group in the moiety, which allowed the interaction of delocalized $\pi$-electrons with empty d-orbital of Fe atom. Inhibition takes place by mixed type adsorption of inhibitor molecules, which followed Langmuir isotherm model. SEM and EDX results confirmed the protective film formation by inhibitor compounds on the metal surface.

Preethi Kumari et al. ${ }^{34}$ have evaluated the corrosion inhibition performance of 2-[(2-methylquinolin-8-yl)oxy]acetohydrazide $\left(\mathrm{HD}_{47}\right)$ in hydrochloric acid $(0.5 \& 1 \mathrm{M})$ media towards mild steel. The inhibition performance of $\mathrm{HD}_{47}$ increased with its concentration. Polarization results indicate the mixed inhibitor behaviour of the compound $\mathrm{HD}_{47}$. Inhibition efficiency of $\mathrm{HD}_{47}$ increased with a rise in temperature in $0.5 \mathrm{M} \mathrm{HCl}$ medium. This indicated the chemisorption of $\mathrm{HD}_{47}$ molecules on the metal surface. However, inhibition efficiency decreased with a rise in temperature in $1 \mathrm{M} \mathrm{HCl}$ medium. This may be due to the highly aggressive nature of acid which overcomes the inhibitory action of the compound at a higher temperature. Further, an increase in temperature might have lead to desorption of inhibitor molecules from the metal surface which resulted in a decrease in inhibitor efficiency. Inhibition process takes place by mixed adsorption and followed Langmuir adsorption isotherm model. The maximum inhibitory efficiency of $91 \%$ (in $0.5 \mathrm{M} \mathrm{HCl}$ at $60^{\circ} \mathrm{C}$ ) and $85 \%$ (in $1 \mathrm{MHCl}$ at $30^{\circ} \mathrm{C}$ ) was obtained at $10^{-3} \mathrm{M}$ concentration of $\mathrm{HD}_{47}$

\section{Mechanism of Corrosion Inhibition}

Generally, inhibition of corrosion of metals takes place by adsorption of inhibitor molecules onto the metal surface. The inhibitor may get adsorbed on the surface either by replacing molecules of a solvent with ions or by replacing molecules of water with inhibitor molecules. The extent of adsorption process possible depends on the physicochemical properties of metal, inhibitor, and medium involved. The types of interaction that can take place during the adsorption of inhibitor may be physisorption or chemisorption or both.

Physisorption usually involves electrostatic forces of attraction between inhibitor molecules and the metal surface. This type of interaction is possible when the electrically charged metal surface, as well as inhibitor species, is present in the corrosive medium. For instance, mild steel surface in hydrochloric acid medium gets a negative charge because of the primary adsorption of chloride ions. This negatively charged surface can attract positively charged protonated inhibitor molecules facilitating physical adsorption. Generally, it is a weak type of adsorption which decreases with increase in temperature. ${ }^{35}$

Chemisorption can take place by sharing or transfer of electrons between inhibitor molecule and metal leading to a co-ordinate bond. Organic inhibitor compounds containing hetero atoms ( $\mathrm{N}, \mathrm{S}$ or $\mathrm{O})$, double or triple bonds and an aromatic ring, and metal containing an empty orbital of lower energy can favour the formation of a coordinate type of bond.$^{36}$ The extent of chemisorption usually increases with a rise in temperature. ${ }^{37}$

\section{Conclusion}

Hydrazide derivatives are found to be the potential acid corrosion inhibitors of mild steel. The majority of hydrazide derivatives have shown mixed inhibitor behaviour controlling anodic as well as cathodic corrosion reactions. Inhibition takes place by adsorption and followed either Langmuir or Temkin isotherm model. The SEM, EDX and FTIR analysis of inhibited mild steel specimen surface confirmed the film formation by the inhibitor molecules on mild steel surface. The inhibition performance of all the hydrazide derivatives increased with their concentration. The performance of some hydrazide derivatives increased and others decreased with increase in acid solution temperature. Hydrazide derivatives with additional hetero atoms (N, O, S), aromatic rings and electron donating groups have shown better inhibition performance. Those hydrazide derivatives which have shown inhibition efficiency greater than $90 \%$ are most suitable for any industrial application as corrosion inhibitors of mild steel.

\section{References}

1 B. Rapp, Corrosion, a study of degradation: an enormous breadth of engineering systems depends upon corrosion protection for their reliability, performance, and safety, Mater. Today, 2006, 9, 6.

2 H.H. Uhlig and R.W. Revie, Corrosion and Corrosion Control: An Introduction to Corrosion Science and Engineering, 3rd edn., John Wiley and Sons, New York, 1991, p. 11. 
3 B. Ridd, T.J. Blakset and D. Queen, Corrosion, NACE, Houston, Texas, 1998, p. 78.

4 R.M. Hudson and C.J. Warning, Factors influencing the pickling rate of hot-rolled low-carbon steel in sulphuric and hydrochloric acids, Met. Finish., 1980, 78, 21-28.

5 M. Behpour, S.M. Ghoreishi, N. Soltani, M. Salavati-Niasari, M. Hamadanian and A. Gandomi, Electrochemical and theoretical investigation on the corrosion inhibition of mild steel by thiosalicylaldehyde derivatives in hydrochloric acid solution, Corros. Sci., 2008, 50, 2172-2181.

6 P.C. Okafor, M.E. Ikpi, I.E. Uwaha, E.E. Ebenso, U.J. Ekpe and S.A. Umoren, Inhibitory action of Phyllanthus amarus extracts on the corrosion of mild steel in acidic media, Corros. Sci., 2008, 50, 23102317.

7 S.J. Keny, A.G. Kumbhar, C. Thinaharan and G. Venkateswaran Gallic acid as a corrosion inhibitor of carbon steel in chemical decontamination formulation, Corros. Sci., 2008, 50, 411-419.

8 R. Narang1, B. Narasimhan and S. Sharma, A review on biological activities and chemical synthesis of hydrazide derivatives, Curr. Med. Chem., 2012, 19, 569-612

9 M. Sainia, P. Kumar, M. Kumar, R. Kalavathy, V. Mani, R.K. Mishra, A.B.A. Majeed and B. Narasimhana, Synthesis, in vitro antimicrobial, anticancer evaluation and QSAR studies of $\mathrm{N}^{\prime}$-(substituted)-4(butan-2-lideneamino)benzo hydrazides, Arabian J. Chem., 2014, 7, $448-460$.

10 M.A. Quraishi, R. Sardar and D. Jamal, Corrosion inhibition of mild steel in hydrochloric acid by some aromatic hydrazides, Mater. Chem. Phys., 2001, 71, 309-313.

11 M.A. Quraishi, N. Saxena and D. Jamal, Inhibition of mild steel corrosion by oleochemical hydrazide, Indian J. Chem. Technol., 2005, 11, 220-224.

12 L. Larabi, Y. Harek, O. Benali and S. Ghalemb, Hydrazide derivatives as corrosion inhibitors for mild steel in $1 \mathrm{M} \mathrm{HCl}$, Progress Org. Coatings, $2005,54,256-262$.

13 A.V. Shanbhag, T.V. Venkatesha, R. Prabhu, R.G. Kalkhambkar and G.M. Kulkarni, Corrosion inhibition of mild steel in acidic medium using hydrazide derivatives, J. Appl. Electrochem., 2008, 38, 279-287.

14 V.R. Saliyan and A.V. Adhikari, Quinolin-5-ylmethylene-3-\{[8 (trifluoromethyl) quinolin-4-yl]thio\}propanohydrazide as an effective inhibitor of mild steel corrosion in $\mathrm{HCl}$ solution, Corros. Sci., 2008, 50, 55-61.

15 V.R. Saliyan and A.V. Adhikari, Corrosion inhibition of mild steel in acid media by quinolinylthiopropanohydrazones, Indian J. Chem. Technol., 2009, 16, 162-174.

16 M.G. Shcherban, T.D. Batueva and A.V. Radushev, N', N'-Dialkylhydrazides as inhibitors of acid corrosion of steel, Russian J. Appl. Chem., 2009, 82, 57-61.

17 S.D. Toliwal and K. Jadav, Inhibition of corrosion of mild steel by phenyl thiosemicarbazides of nontraditional oils, J. Sci. Ind. Res., 2010, 69, 43-47.

18 K.F. Khaled, O.A. Elhabib, A. El-mghraby, O.B. Ibrahim and M.A.M. Ibrahim, Inhibitive effect of thiosemicarbazone derivative on corrosion of mild steel in hydrochloric acid solution, J. Mater. Environ. Sci. 2010, 1, 139-150

19 P. Mohan, R. Usha, G.P. Kalaignan and V.S. Muralidharan, Inhibition effect of benzo hydrazide derivatives on corrosion behaviour of mild steel in $1 \mathrm{M} \mathrm{HCl}$, J. Chem., 2013, 2013, 1-7.

20 M.P. Chakravarthy and K.N. Mohana, Inhibition behaviour of some isonicotinic acid hydrazides on the corrosion of mild steel in hydrochloric acid solution, Inter. J. Corros., 2013, 2013, 1-13 .

21 A.S. Fouda, M.T. Mohamed and M.R. Soltan, Role of some benzo hydrazide derivatives as corrosion inhibitors for carbon steel in $\mathrm{HCl}$ solution, J. Electrochem. Sci. Technol., 2013, 4, 61-70.

22 C.B. Pradeep Kuma and K.N. Mohana, Corrosion inhibition efficiency and adsorption characteristics of some Schiff bases at mild steel/hydrochloric acid interface, J. Taiwan Inst. Chem. E., 2014, 45, 1031-1042.

23 S.R. Gupta, P. Mourya, M.M. Singh and V. P. Singh, Synthesis, structural, electrochemical and corrosion inhibition properties of two new ferrocene Schiff bases derived from hydrazides, J. Organometa. Chem., 2014, 767, 136-143.

24 P. Preethi Kumari, P. Shetty, A. Suma Rao and S. Dhanya, Corrosion inhibition and adsorption behaviour of (2E)-2-(3-hydoxy-2-methoxybenzilidene)hydrazine carbothiamide on mild steel $1 \mathrm{M} \mathrm{HCl}$, Rev. Roum. Chim., 2014, 59, 323-333.

25 P. Preethi Kumari, P. Shetty and A. Suma Rao, Electrochemical investigation of hydrazide derivative as corrosion inhibitor for mild steel in hydrochloric acid medium, Indian J. Chem. Technol., 2016, 23, 196-203.

26 P. Preethi Kumari, P. Shetty and A. Suma Rao, Electrochemical measurements for the corrosion inhibition of mild steel in $1 \mathrm{M}$ hydrochloric acid by using an aromatic hydrazide derivative, Arabian J. Chem., 2017, 10, 653-663.

27 P. Preethi Kumari, A. Suma Rao and P. Shetty, Corrosion inhibition of mild steel in $2 \mathrm{M} \mathrm{HCl}$ by a Schiff base derivative, Proc. Mater. Sci., 2014, 5, 499-507.

28 P. Preethi Kumari, P. Shetty and A. Suma Rao, Corrosion inhibition effect of 4-hydroxy- $\mathrm{N}^{\prime}$-[(E)-(1H-indole-2-ylmethylidene)] benzo hydrazide on mild steel in hydrochloric acid solution, Inter. J. Corros., 2014, 2014, 1-11.

29 P. Preethi Kumari, P. Shetty and A. Suma Rao, Corrosion protection properties of 4-hydroxy $\mathrm{N}^{\prime}$-[(1E, 2E)-3-phenylprop-2-en-1-ylidene] benzohydrazide on mild steel in hydrochloric acid medium, Prot. Met. Phys. Chem. Surf., 2015, 51, 1034-1042.

30 M. Yadav, R.R. Sinha, S. Kumar, I. Bahadur and E.E. Ebenso, Synthesis and application of new aceto hydrazide derivatives as a corrosion inhibition of mild steel in acidic medium: insight from electrochemical and theoretical studies, J. Mol. Liq., 2015. 208, 322-332.

31 Z.A. Abdallah, M.S. Mohamed Ahmed and M.M. Saleh, Organic synthesis and inhibition action of novel hydrazide derivative for mild steel corrosion in acid solutions, Mater. Chem. Phys., 2016, 174, 91-99.

32 A.A. Al-Amiery, F.A. Binti Kassim, A.1A.H. Kadhum and A.B. Mohamad, Synthesis and characterization of a novel eco-friendly corrosion inhibition for mild steel in $1 \mathrm{M}$ hydrochloric acid, Sci. Rep., 2016, 1-13.

33 N.K. Mohd, M.J. Ghazali, Y.S. Kian, N.A. Ibrahim, W.M.Z.W. Yunus, S.M.M. Nor and Z. Idris, Corrosion inhibition of mild steel in hydrochloric acid solution using fatty acid derivatives, J. Oil Palm Res.,2017, 29, 97-109.

34 P. Preethi Kumari, P. Shetty and A, Suma Rao, Inhibition behaviour of 2-[(2-methylquinolin-8-yl) oxy] aceto hydrazide on the corrosion of mild steel in hydrochloric acid solution, Trans. Indian Inst. Met., 2017, 70, 11391150.

35 F.B. Mansfeld, Corrosion Mechanisms, Taylor \& Francis, 1986.

36 D. Landolt, Corrosion and Surface Chemistry of Metals, EPFL Press, Switzerland, 2007.

37 A.S. Khanna, Introduction to High-Temperature Oxidation and Corrosion, ASM International, Materials Park, Ohio, 2002. 